\title{
Perforation repair of Mandibular Molar with five canals: A Case Report.
}

\author{
${ }^{1}$ Dr.Mahendra Patel, ${ }^{2}$ Dr.Aditi Soni, ${ }^{2}$ Dr.Anjali Oak \\ ${ }^{1,2}$ (DepartmentOf Conservative Dentistry and Endodontics, CDSRC, Gujarat University,India)
}

\begin{abstract}
Perforation in the furcalarea is the most common iatrogenic error caused while looking for extra canals during access cavity preparation. Successful management of perforation depends on many factors including location of perforation, time delay, previous contamination, ability to seal the defect ${ }^{l}$. If not managed successfully, prognosis is poor. Perforation repair poses more difficulty to the operator when tooth has anatomical variations. The present case report describes perforation repair in mandibular molar with five canals.
\end{abstract}

Keywords: MTA, Perforation repair, Mandibular molar with five canals

\section{Introduction}

Perforations in root canal systems may be a result of iatrogenic errors such as misaligned use of rotary burs during endodontic access preparation and search for root canal orifices or due to pathologic process such as caries and root resorption. ${ }^{2} \mathrm{~A}$ good prognosis can be expected in case of fresh, small, coronal, and apical perforation. ${ }^{2,3}$ To repair such perforations, a material with good sealability might be used to prevent continuous exposure to a contaminating environment. ${ }^{4}$ Knowledge of possible variations in root canal morphology is important to avoid such errors in first place.Incomplete instrumentation, inadequate cleaning and shaping, and the subsequent defective obturation of root canals are the main causes of endodontic treatment failure. ${ }^{5}$ Anatomical characteristics of the different types of teeth and their possible variations are challenges routinely faced by practitioners performing endodontic treatment. The present case report is about managing such iatrogenic error in a tooth which also has canal variation.

\section{Case Report}

A 32 year old patient presented with a complaint of pain in lower right back tooth region since four days which aggravated on chewing. Patient had history of previous incomplete root canal treatment in the same tooth. The tooth was tender on percussion and showed radiolucency over furcal and apical area along with widening of periodontal ligament space on Pre-operative radiograph (Fig. 1). On removal of old restoration, furcalperforation over mesial area between mesiobuccal and distobuccal canal orifice was observed. Diagnosis of acute apical periodontitis with furcal perforation was made. Access cavity preparation was refinedunder local anesthesia (Inferior alveolar nerve block) (Fig.2), wherein mid-distal canal opening was observed. Canal patency was established with no. $10 \mathrm{k}$ file.

Working length was determined with no. 15 k-file (Fig 3). Bio-mechanical preparation was completed using Protaper rotary filesupto F2 (DentsplyMaillefer, Switzerland) in crown-down fashion as per manufacturer's recommendation. 2.5\% Sodium hypochlorite and Normal saline were used as irrigants during preparation of the canals. Calcium Hydroxide powder was mixed with normal saline and placed over the perforation area. Calcium hydroxideintracanal medicament was given and patient was recalled after 7 days.Intracanal medicament was changed twice in the subsequent appointments and once the patient was asymptomatic, root canal obturation was carried out withProtaperguttaperchacone F2 (DentsplyMaillefer, Switzerland). (Fig. 4) Perforation was then sealed with white MTA (Pro-root,DentsplyMaillefer, Switzerland) (Fig.5). Post-endodontic restoration was done (Fig 6) and patient was recalled for follow up wherein patient was absolutely asymptomatic. 


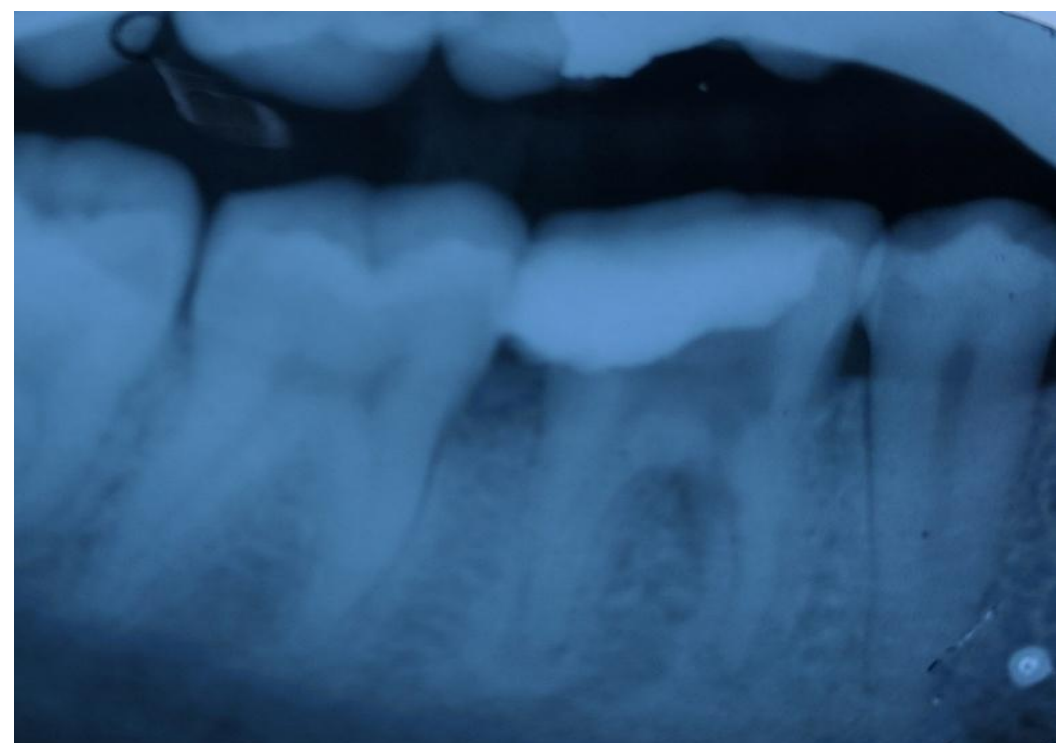

(Figure 1: Pre-operative radiograph)

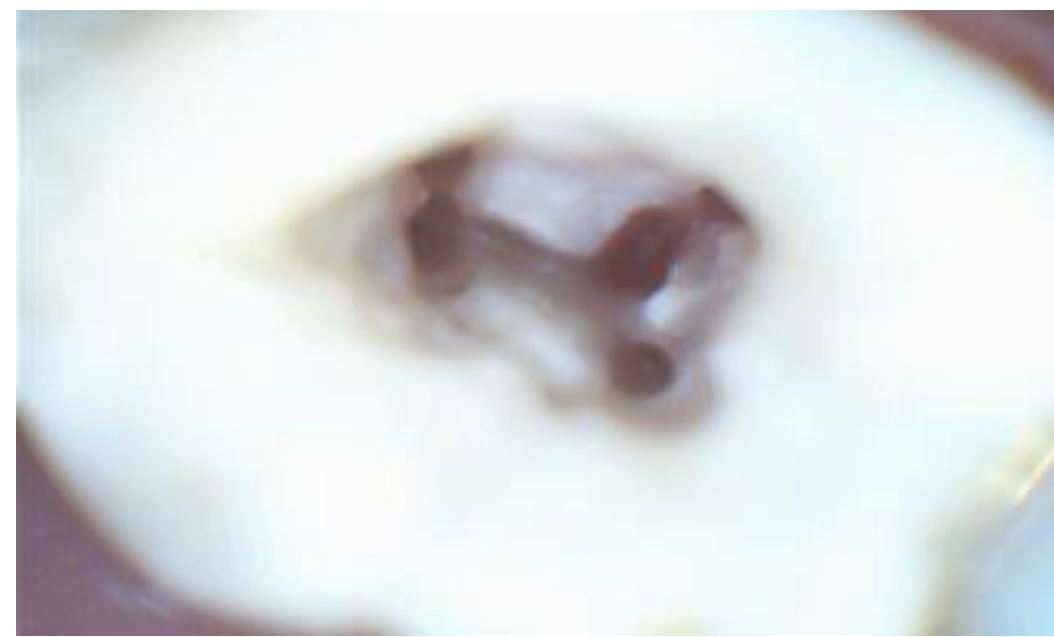

(Figure 2: Access cavity preparation)

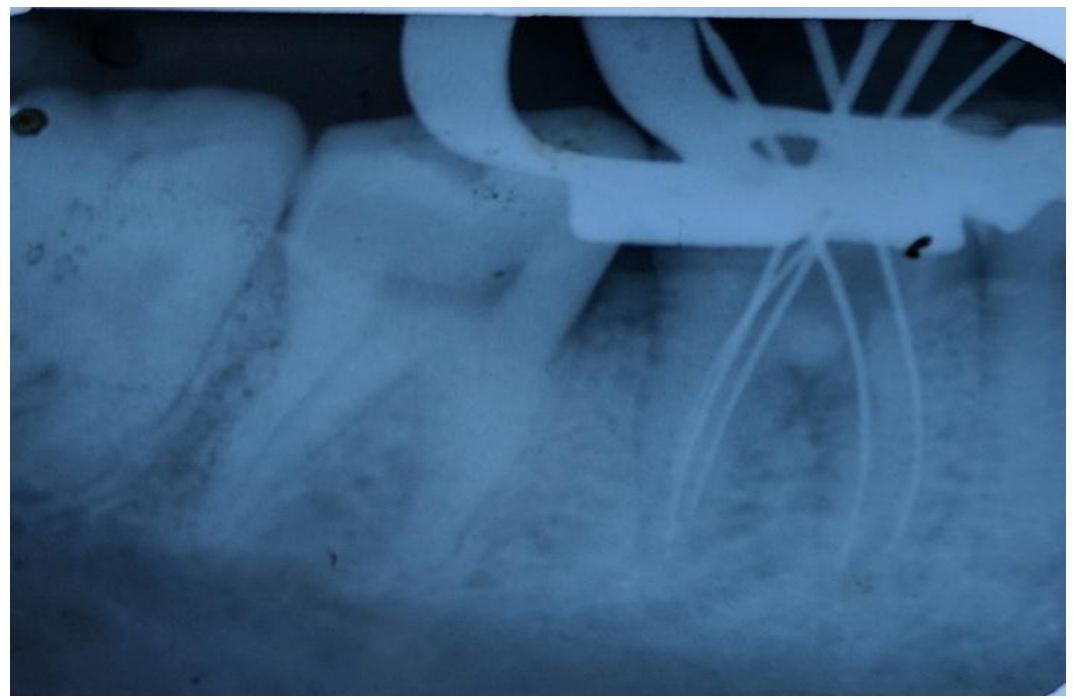

(Figure 3: Working length radiograph) 


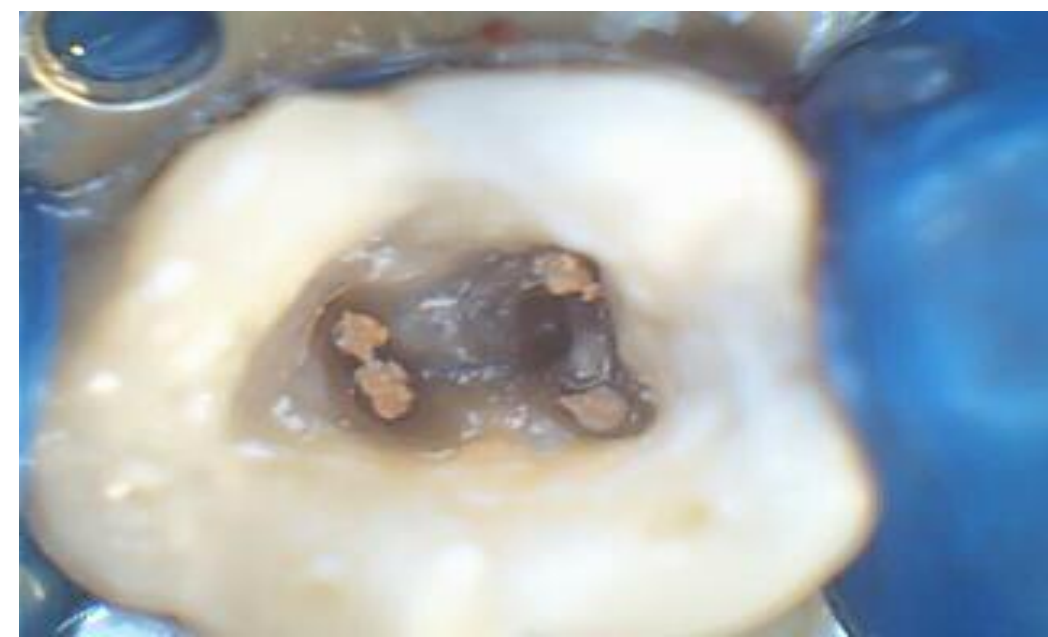

(Figure 4:Obturation of canals)

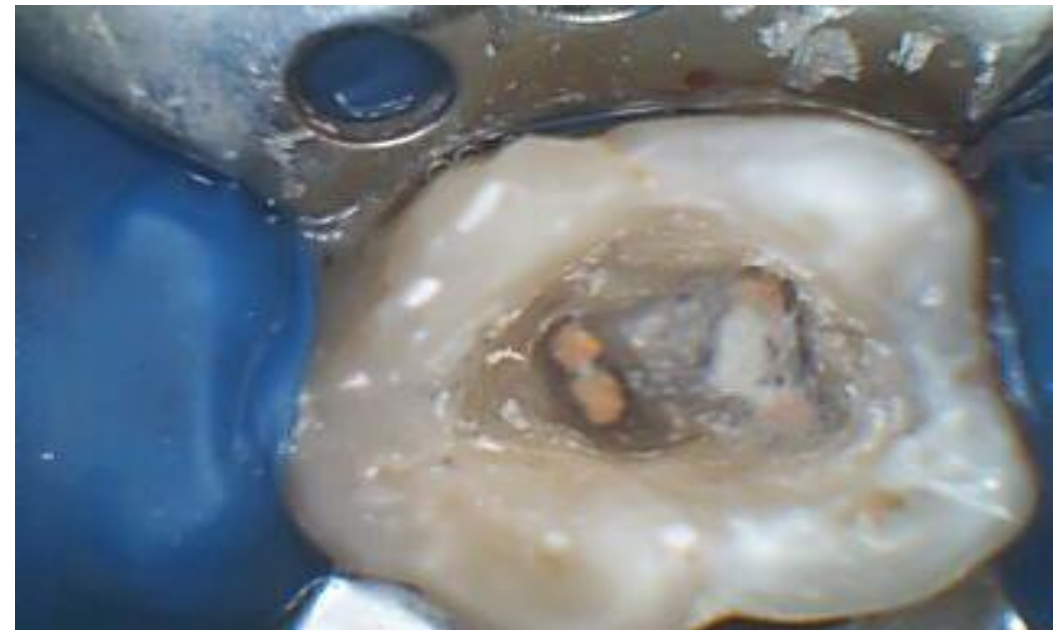

(Figure 5: Perforation repair with MTA)

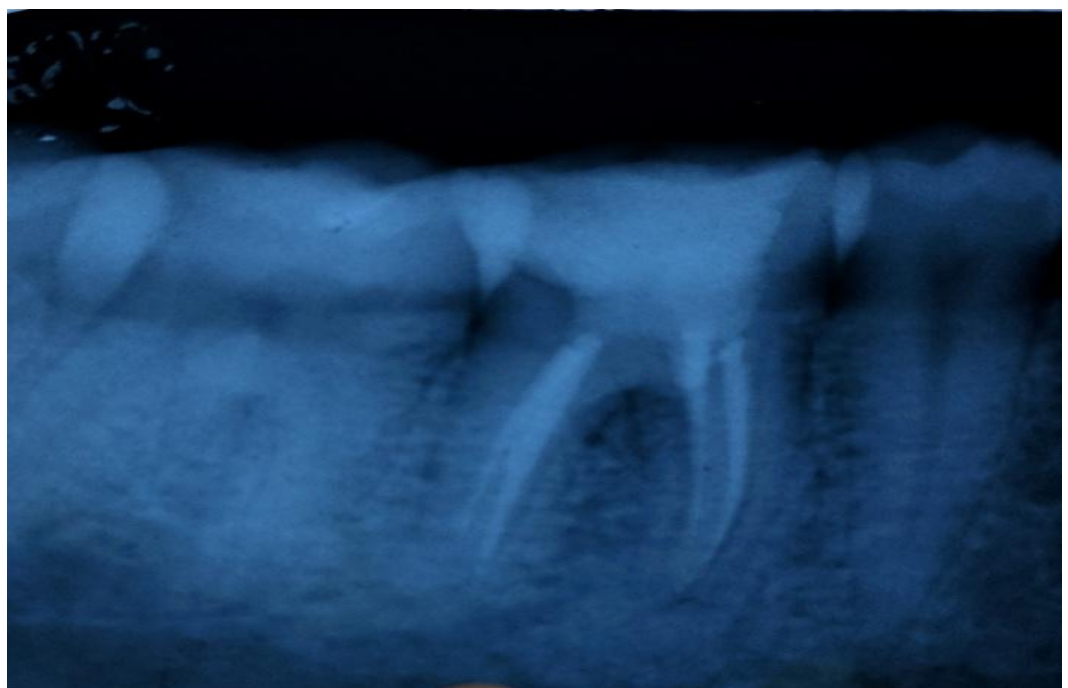

(Figure 6: Post-operative radiograph) 


\section{Discussion}

To achieve success in root canal treatment, it is necessary to have knowledge not only of normal root canal morphology but also of its variants so as to achieve optimal biomechanical preparation. Jacobsen et al. found a substantial rate of occurrence of a third mesial canal in mandibular first molars, and reported that 12 out of the 100 molars studied had a third mesial canal. ${ }^{6}$ According to Ingle, one of the most important causes of endodontic treatment failure is the incomplete obturation of the root canal system. ${ }^{1}$ Hence, the correct identification, instrumentation and obturation of all canals are indispensable procedures.Procedural error is one of the most common reason for furcalperforation. The purpose of treating furcal perforation is to seal the artificial communication between the endodontic space and the periradicular tissue to prevent alveolar bone resorption and damage to the periodontal ligament. When MTA was used to seal intentional furcal perforations in dogteeth,cementum was formed over the MTA; furthermore, there was no inflammatory cells infiltrate. ${ }^{7}$

In addition, the material ofchoicefor repairingroot perforations should be nontoxicand insoluble in the presence of moisture, and it should be able to promote the healing of the periradicular tissue.Mineral trioxide aggregate (MTA) is a calcium silicate based material that sets in presence of moisture and has superior sealing property. Perforations if not repaired can lead to complications that necessitate extraction of theinvolved tooth. A study of the reasons for extraction of endodontically treated teeth suggestedthat some $4.2 \%$ of teeth were extracted because of iatrogenic perforations andstripping ${ }^{9}$. Bacterial infection emanating from the root canal, the periodontal tissues,or both would prevent healing and bring about inflammatory sequels including pain,swelling, suppuration, and bone resorption.Repair of perforation was done under rubber dam isolation as Rubber dam has been known to serve various advantages such as protection of patient against aspiration of instrument, prevents laceration of soft tissue from rotary or hand instrument, improves accessibility and visibility, retraction of soft tissue to some extent, and also precludes cross infection. ${ }^{11}$ The complexity of treatment in such a case necessitates accurate clinical procedures for favourable outcome.

\section{Conclusion}

A reasonably favourable prognosis for accurately prepared root canal treated teeth can be expected by repairing thefurcalperforation with MTA.

\section{Acknowledgements}

None

\section{Conflict Of Interest}

None

\section{References}

[1]. Ingle JI. Endodontics. 3rd ed. Philadelphia, PA: Saunders; 1985

[2]. Sinai IH. Endodontic perforations: their prognosis and treatment. J Am Dent Assoc 1977;95:90 -5. 3. Fuss Z, Trope M.

[3]. Root perforations: classification and treatment choices based on prognostic factors. Endod Dent Traumatol 1996;12:255-64.

[4]. Seltzer S, Sinai I, Augusr D. Periodontal effects of root perforations before and during endodontic procedures. J Dent Res 1970;49:332-9.

[5]. Leonardo MR. Aspectosanatômicos da cavidadepulpar: relações com o tratamento de canaisradiculares. In: Leonardo MR, Leal JM, eds. Endodontia: tratamento de canaisradiculares. 3rd ed. São Paulo: Panamericana; 1998. p. 191.

[6]. Jacobsen EL, Dick K, Bodell R. Mandibular first molars with multiple mesial canals. J Endod 1994; 20: 610-13.

[7]. Pitt Ford TR, Torabinejad M, McKendry DJ, Hong CU, Kariyawasam SP. Use of mineral trioxide aggregate for repair of furcal perforations. Oral Surg Oral Med Oral Pathol Oral RadiolEndod 1995;79:756 - 62.

[8]. Alhadainy HA. Root perforations. Oral Surg Oral Med Oral Pathol Oral RadiolEndod 1994;78:368 -74.

[9]. Toure B, Faye B, Kane AW, et al. Analysis of reasons for extraction of endodonticallytreated teeth: a prospective study. J Endod 2011;37:1512-5.

[10]. Tsesis I, Fuss ZV. Diagnosis and treatment of accidental root perforations. EndodTopics 2006;13:95-107.

[11]. Ahmad IA. Rubber dam usage for endodontic treatment: a review. IntEndod J. 2009; 42:963-72. 